\title{
Questão racial e formação profissional em Serviço Social ${ }^{1}$
}

\author{
Cuestión Social y formación profesional en Servicio Social \\ The racial question and professional formation in Social Service
}

\begin{abstract}
Angela Carvalho de Almeida Coelho ${ }^{2}$, Bernardo dos Santos Gomes de Oliveira ${ }^{3}$, Luana Fernandes Pereira ${ }^{4}$, Marco Antonio da Silva Santos ${ }^{5}$ e Vanessa Bezerra de Souza ${ }^{6}$.
\end{abstract}

\begin{abstract}
Resumo
Racismo é a crença na existência das raças naturalmente hierarquizadas pela relação intrínseca entre o físico e o moral, o físico e o intelecto, o físico e o cultural. No Brasil - país colonizado, tendo escravizado a mão de obra negra por 354 anos - tem enraizado em sua estrutura social o racismo. A partir dos anos 1930, houve um investimento ideológico no sentido de romantizar a miscigenação, originando o chamado mito da democracia racial. Contudo, a população negra continuou à margem de qualquer iniciativa estatal no sentido de garantir acesso ao trabalho, à educação e à infraestrutura básica. A Questão Social - base de fundamentação da existência do Serviço Social - é entendida como o conjunto de problemas econômicos, sociais, políticos, culturais e ideológicos que cerca o surgimento da classe trabalhadora como sujeito sócio-político no marco da sociedade capitalista, classe trabalhadora essa que no Brasil é majoritariamente negra. O projeto ético-político do Serviço Social vincula-se a um projeto societário que privilegia a centralidade das determinações de classe, gênero, e etnia, que se propõe à construção de uma nova ordem social, à defesa intransigente dos direitos humanos e à recusa do arbítrio e dos preconceitos. Compõe ainda esse projeto o compromisso com a "competência" profissional, demandando uma formação acadêmica qualificada, que tenha por base concepções teóricometodológicas sólidas e críticas que viabilizem uma análise concreta da realidade social. Deve-se, portanto, investir no âmbito da formação profissional em pesquisas acerca da questão racial no Brasil para contribuir com a superação do racismo.
\end{abstract}

Palavras-Chave: Formação Profissional; Questão Social; Racismo; Serviço Social

\section{Resumen}

Racismo es la creencia en la existencia de las razas naturalmente jerarquizadas por la relación intrínseca entre lo físico y lo moral, lo físico y lo intelecto, lo físico y lo cultural. En Brasil-país colonizado, habiendo esclavizado la mano de obra negra por 354 años- ha enraizado en su estructura social el racismo. A partir de los años 1930,

\footnotetext{
${ }^{1}$ Artigo apresentado no Simpósio Temático (RELAÇÕES ÉTNICO-RACIAIS NA AMÉRICA LATINA: DEBATES INTERSECCIONAIS NA DIÁSPORA) durante o II Seminário Latino-Americano de Estudos em Cultura - SEMLACult em Foz do Iguaçu/PR, Brasil, 2018.

${ }^{2}$ Graduanda de Serviço Social; Universidade Federal do Estado do Rio de Janeiro - UNIRIO; Rio de Janeiro, Rio de Janeiro, Brasil; acacangela@gmail.com.

${ }^{3}$ Graduando de Serviço Social; Universidade Federal do Estado do Rio de Janeiro - UNIRIO; Rio de Janeiro, Rio de Janeiro, Brasil; oliveirabsg@gmail.com.

${ }^{4}$ Graduanda de Serviço Social; Universidade Federal do Estado do Rio de Janeiro - UNIRIO; Rio de Janeiro, Rio de Janeiro, Brasil; multiluana@gmail.com.

${ }^{5}$ Graduando de Serviço Social; Universidade Federal do Estado do Rio de Janeiro - UNIRIO; Rio de Janeiro, Rio de Janeiro, Brasil; marcosilva.nave@gmail.com.
}

${ }^{6}$ Pós-doutora em Serviço Social, Universidade Federal do Estado do Rio de Janeiro - UNIRIO; Rio de Janeiro, Rio de Janeiro, Brasil; vsouza76@gmail.com. 
hubo una inversión ideológica en el sentido de romantizar el mestizaje, originando el llamado mito de la democracia racial. Sin embargo, la población negra continuó al margen de cualquier iniciativa estatal para garantizar el acceso al trabajo, la educación y la infraestructura básica. La cuestión social - base de fundamentación de la existencia del Servicio Social - es entendida como el conjunto de problemas económicos, sociales, políticos, culturales e ideológicos que rodean el surgimiento de la clase trabajadora como sujeto sociopolítico en el marco de la sociedad capitalista, clase trabajadora que en Brasil es mayoritariamente negra. El proyecto ético-político del Servicio Social se vincula a un proyecto societario que privilegia la centralidad de las determinaciones de clase, género, y etnia, que se propone a la construcción de un nuevo orden social, a la defensa intransigente de los derechos humanos y al rechazo del mismo, el arbitrio y los prejuicios. También compone este proyecto el compromiso con la "competencia" profesional, demandando una formación académica calificada, que tenga por base concepciones teórico-metodológicas sólidas y críticas que viabilicen un análisis concreto de la realidad social. Se debe, por lo tanto, invertir en el ámbito de la formación profesional en investigaciones acerca de la cuestión racial en Brasil para contribuir con la superación del racismo.

Palabras claves: Formación Profesional; Cuestión Social; Racismo; Servicio Social.

\begin{abstract}
Racism is the belief in the existence of races naturally hierarchized by the intrinsic relationship between the physical and the moral, the physical and the intellectual, the physical and the cultural. In Brazil - a colonized country, having had enslaved the black labor force for 354 years -, racism has its roots in its social structure. Since the 1930s, there was an ideological investment in the sense of romanticizing miscegenation, originating the so-called "myth of racial democracy". However, the black population has remained at the margin of any state initiative to guarantee access to work, education and basic infrastructure. The Social Question - the basis for the foundation of the existence of Social Service - is understood as the set of economic, social, political, cultural and ideological problems which surrounds the emergence of the working class as a socio-political subject within the framework of capitalist society, a working class which in Brazil is mostly black. The ethical-political project of Social Service is linked to a societal project that privileges the centrality of determinations of class, gender, and ethnicity, which proposes itself to the build a new social order, to the uncompromising defense of human rights and to the refusal of constraint and preconceptions. This project also includes a commitment to professional "competence", demanding a qualified academic formation, that is based on solid and critical theoretical and methodological concepts, that make possible a concrete analysis of the social reality. It is therefore necessary to invest in professional formation in research on the racial question in Brazil to contribute to the overcoming of racism.
\end{abstract}

Keywords: Professional Formation; The Social Question ; Racism; Social Service

\title{
1. Introdução
}

Considerando a formação social e histórica do Brasil, sobretudo a partir da utilização do trabalho escravo e da exploração de suas riquezas em sua fase de colonização, é inegável a presença de práticas racistas, presentes até os dias atuais. Santos (2015) afirma que duas estratégias foram utilizadas pela elite brasileira, e que tornou a questão do racismo algo estruturante em nossa sociedade: a ideologia do branqueamento e o mito da democracia racial.

A primeira foi concretizada no pós-abolição, com o investimento na imigração de trabalhadores europeus, em detrimento da utilização da mão de obra negra recém liberta. A partir dos anos de 1930, passamos a ser considerada uma nação divinamente mestiça, o que deu origem ao chamado mito da democracia racial. Mito posto que se constituísse enquanto 
representação retórica, já que a população negra continuou à margem de qualquer iniciativa estatal no sentido de lhes garantir acesso ao trabalho ao lazer, à educação e à infraestrutura básica.

A discussão sobre a formação profissional em Serviço Social se pauta na "questão social" enquanto eixo fundamental para a compreensão da profissão, questão essa que se revela por meio de suas "refrações", sobre as quais o assistente social, a partir de uma prática pensada e refletida, realiza intervenções apoiadas em políticas sociais, cuja finalidade é oferecer respostas às expressões multifacetadas e complexas da "questão social" no capitalismo.

Quando se fala em "questão social” não se está falando apenas em suas determinações econômicas, pois as mudanças na esfera da produção operam refrações nos mecanismos de reprodução social, âmbito privilegiado da intervenção do Serviço Social. Produção e reprodução constituem faces de um mesmo sistema produtivo, uma vez que todo modo de produção não pode prescindir da produção de meios de subsistência nem da reprodução de seres humanos. Os processos de produção e reprodução imbricam-se mutuamente e são definidos com base no caráter contraditório das relações de gênero, de "raça" e entre as classes sociais.

Esse caráter contraditório é encontrado tanto na produção quanto na reprodução da vida social, de modo que as relações de gênero, de "raça" e de classe se permeiam, dando forma a uma divisão do trabalho, social, racial e sexualmente determinada, tanto no âmbito da produção quanto no da reprodução.

Contudo, o debate étnico-racial ainda não está sendo considerado como obrigatório para a grande maioria das Unidades Acadêmicas de Serviço Social em nível nacional. Desta forma, a presente pesquisa visa mapear as Escolas de Serviço Social das Universidades públicas Brasileiras, no sentido de avaliar se as mesmas estão oferecendo o debate a respeito das questões em tela, analisando os projetos político-pedagógicos, currículos e ementas das disciplinas. Apresentar o Estado da Arte destes debates na formação profissional de Serviço Social se faz imprescindível no sentido de contribuir para a qualidade da formação profissional consoante com o projeto ético político profissional comprometido com a emancipação humana.

\section{Contextualização}

\subsection{O racismo na formação sócio-histórica brasileira}


O racismo é uma crença na existência das raças hierarquizadas pela relação intrínseca entre o físico e o moral, o físico e o intelecto, o físico e o cultural. Para o racista, a raça não é somente um grupo definido pelos seus traços físicos, o racismo é a direção que considera que as características intelectuais e morais de um grupo estão ligadas às suas características físicas e biológicas. A maneira como as justificativas da escravidão foram dadas têm origens míticas, históricas e até bíblicas e que perpassam pela questão do racismo.

No século XVI com o investimento do Estado Português na colonização da América, e a necessidade de mão de obra, para o uso da escravidão existiam justificativas religiosas e econômicas. Por trás das justificativas religiosas estavam as reais intenções dos portugueses, e assim podemos pensar na justificativa econômica. Os portugueses eram voltados para o comércio e, quando em meados do século XVI houve uma queda no comércio no Oriente, os grandes comerciantes de Portugal passaram a investir intensamente no comércio de escravos africanos. Eles pressionavam a Coroa para o investimento de um tipo de colonização da América que gerasse uma demanda grande de mão de obra, a mão de obra escravizada.

Os negros não aceitaram a sua condição de escravizados, naturalmente, e houveram fugas individuais e em massa. A resistência dos escravos contra a escravidão, junto à pressão da Inglaterra pelo fim dessa forma de "trabalho", fez com que o Império Brasileiro publicasse algumas leis que levariam à abolição da escravidão e na libertação dos escravizados.

Apesar da Independência, em 1822, a escravidão continuou a vigorar no país até a promulgação da Lei Áurea, em 1888. Na América, o Brasil foi o último país a abolir a escravidão. A Lei Áurea nunca discutiu o que fazer com aqueles que até então eram escravos, eles foram abandonados à própria sorte. A estratégia adotada no Brasil foi a imigração de europeus, oferecendo a eles exatamente o que se propunha que se desse aos ex-escravizados: um pedaço de terra e um salário para trabalharem.

Esta escolha estratégica gerou ex-escravizados sem acesso à terra e sem qualquer tipo de indenização por tanto tempo de trabalhos forçados, geralmente analfabetos, vítimas de todo tipo de preconceito. Muitos permaneceram nas fazendas em que trabalhavam, vendendo seu trabalho em troca da sobrevivência; aos que migraram para as cidades, só restaram os subempregos, a economia informal e o artesanato.

Com isso, aumentou significativamente o número de ambulantes, empregadas domésticas, quitandeiras sem qualquer tipo de assistência e garantia; muitas ex-escravizadas eram tratadas como prostitutas. Os negros que não moravam nas ruas passaram a morar, quando muito, em míseros cortiços. 
As consequências da escravização e da falta de apoio aos negros no pós abolição, refletem, e muito na situação da população negra na atualidade. Um grande problema enfrentado pelos negros no Brasil é a necessidade constante de justificação da luta pela sua emancipação. Se antes era uma verdade absoluta a desqualificação, hoje o discurso se concentra em (1) que inexiste racismo e (2) falar da diferença é errado porque todos são iguais.

Essa ideia vem do mito da democracia racial, que é estruturada na obra Casa Grande \& Senzala, de Gilberto Freyre (2003): Propunha-se que a miscigenação seria um processo de enriquecimento racial e cultural dos povos, que seria feita de forma democrática e livre. Porém, nesse processo, a dignidade da mulher negra foi violentada, na esfera moral e sexual, através de uniões à força, sob o medo e insegurança impostos, onde seus filhos eram criados legalmente sem pai, não havendo, assim, nenhum enriquecimento racial e cultural de civilização.

Ultimamente, os sistemas de cotas e a criação de um ministério voltado para questão racial demonstram o tamanho de nosso problema. Aceitamos a distinção do negro do moreno, em uma aquarela de tons onde o último ocupa uma situação melhor que a do primeiro. Isso nos indica que o alcance da democracia é um assunto tão difícil e complexo como a nossa relação com o negro no Brasil. Ou seja, porque o Estado assume a ausência de preconceito racial, ele não consegue fazer cumprir as poucas leis para combater a discriminação racial, pois acredita que tais esforços sejam desnecessários.

\subsection{Questão Étnico-Racial e a Formação Profissional em Serviço Social}

Para o Serviço Social, a condição histórica que levou a construção de um projeto político e seus 11 princípios éticos, teve seu início com a problematização do conservadorismo. Após a intervenção militar, já nos anos oitenta surgiram grandes movimentos de cunho popular, trazendo a exigência de transformações políticas, sociais e democráticas. Com isso, o corpo profissional foi rompendo com o monopólio do conservadorismo no Serviço Social; E a sociedade na conquista da democracia política abriu espaço para debates entre projetos de sociedade distintos, que se confrontam até hoje no movimento das classes sociais.

Atualmente, o projeto societário em que se orienta a nossa profissão constitui uma nova ordem social, distinta da atual, baseado na defesa dos direitos humanos e contrário a todo e qualquer preconceito, sendo favorável ao pluralismo societário e profissional. Fazemos 
correspondência aos princípios éticos fundamentais do nosso Código de Ética (1993): Por mais contraditório que seja, o Serviço Social trabalha em função do capital, porém, a direção social do Serviço Social aponta para um projeto profissional e um projeto societário diferente da classe dominante. E com isso o código nos dá a orientação do trabalho profissional a partir de valores que estão vinculados à vida cotidiana e as lutas sociais.

A construção de uma nova ordem societária sem dominação e exploração de classe, etnia e gênero requer um compromisso claro com o processo de emancipação humana, com a produção cotidiana das condições sociais que possibilitem um progressivo e radical processo de autodeterminação dos sujeitos, seja na condição de indivíduos singulares como é, sobretudo, humano-genérico.

À luz das ideias gramscianas, acreditamos na esfera educacional enquanto formadora da consciência crítica, e espaço de emancipação do indivíduo, isto posto, para o curso de Serviço Social, se faz imprescindível possuir os pressupostos norteadores da concepção de formação profissional, disseminado em suas disciplinas contidas nas ementas curriculares, que implicam na capacitação teórico-metodológica, ético-política e técnico-operativa da profissão.

O debate a respeito da questão étnico-racial encontra-se vinculado ao Núcleo de Fundamentos da Formação Sócio-histórica da sociedade brasileira; possuir esta análise nos direciona para a apreensão dos movimentos que proporcionaram a consolidação de padrões do desenvolvimento capitalista no país, com seus impactos econômicos, sociais e políticos peculiares à nossa sociedade, tais como suas desigualdades sociais, diferenciação de classe, de gênero e étnico raciais, exclusão social, etc.

Ou seja, este conteúdo implica na análise constante e atenta da conjuntura dessa sociedade, tendo grande importância para o acompanhamento das relações sociais decorrentes das múltiplas manifestações da questão social. E para além, auxilia na compreensão do profissional desta categoria, e determina sua horizontalidade no campo da ação profissional, em face de uma nova compreensão de sociedade, livre das condicionantes discriminatórias.

Discriminar é violar direitos e o princípio da não discriminação, assim como os demais princípios defendidos no Código de Ética do Assistente Social acenam para uma práxis social, na qual a ação profissional está fundamentada em uma concepção ética que tem como fundamento ontológico o ser social.

Neste sentido, o "empenho na eliminação de todas as formas de preconceitos, o respeito à participação de grupo socialmente discriminado e a discussão das diferenças", deve 
ser um princípio ético-político defendido por todos os indivíduos e profissionais comprometidos (as) com a construção de uma sociedade verdadeiramente emancipada.

\section{Objetivos}

Fazer um resgate histórico a respeito do Serviço Social sobretudo a partir de sua fase crítica, ou seja, a partir de meados da década de 70. Analisar as diretrizes curriculares elaboradas pela associação brasileira de ensino, pesquisa e extensão em Serviço Social no sentido de destacar em que medida as mesmas preveem a relevância do debate étnico-racial; Analisar a história do racismo na sociedade brasileira, a partir da produção teórica sobre o tema.

Analisar os projetos político-pedagógicos das escolas de Serviço Social públicas brasileiras no sentido de mapear a presença ou não da questão étnico-racial; Analisar as grades curriculares das escolas de Serviço Social brasileiras no sentido de mapear quais oferecem o debate da questão étnico-racial na forma de disciplinas obrigatórias ou eletivas; Analisar as ementas das disciplinas oferecidas no sentido de perceber qual perspectiva teórica o debate da questão étnico-racial está sendo encaminhado.

\section{Resultados esperados}

Espera-se apresentar o "Estado da Arte" do ensino da questão étnico-racial nas escolas de Serviço Social nas universidades públicas brasileiras, assim como incidir junto às entidades representativas de Serviço Social, sobretudo a ABEPSS - Associação Brasileira de Ensino e Pesquisa em Serviço Social -, no sentido de demonstrar a importância do debate da questão étnico-racial para a formação profissional em Serviço Social. Também se espera socializar o conhecimento acumulado com a realização da pesquisa, no sentido de demonstrar a relevância da questão étnico-racial junto à categoria de assistentes sociais, a partir da produção de artigos e apresentação em congressos e seminários regionais e nacionais.

\section{Conclusões}

A Assembleia Geral da ONU proclamou o período entre 2015 e 2024 como a Década Internacional de Afrodescendentes, citando a necessidade de reforçar a cooperação nacional, 
regional e internacional em relação ao pleno aproveitamento dos direitos econômicos, sociais, culturais, civis e políticos de pessoas de afrodescendentes, bem como sua participação plena e igualitária em todos os aspectos da sociedade. O tema da campanha é: Povos Afrodescendentes: Reconhecimento, justiça e desenvolvimento.

Com relação à profissão, possuímos o Conselho Federal de Serviço Social (CFESS) que atua na orientação, normatização, fiscalização e defesa do exercício profissional do/a assistente social no Brasil, em conjunto com os Conselhos Regionais de Serviço Social (CRESS). Nos últimos 30 anos, a entidade vem promovendo ações que possuem como norte a construção de um projeto de sociedade radicalmente democrático, anticapitalista e em defesa dos interesses da classe trabalhadora.

A atual gestão - É de batalhas que se vive a vida - lançou campanha para o triênio 2017-2020, juntamente com os Conselhos Regionais de Serviço Social de todo o país: "Serviço Social no combate ao Racismo". Com esta campanha, é reconhecido o caráter basilar que o racismo possui vinculado à formação social brasileira, tendo o povo negro como centro da maior exploração no país. Reconhece a experiência da escravidão como crime que infringiu direitos intrínsecos da população negra, tornando-se indispensável a reparação imediata às perdas dessa população, entendendo que combater o racismo é tarefa da nossa categoria no exercício profissional cotidiano, enquanto este tipo de preconceito ainda se reproduzir nas instituições em que assistentes sociais atuam.

O último Encontro Nacional de Pesquisadores em Serviço Social (ENPESS) que ocorreu em Vitória em 2018 teve como tema central a questão étnico/racial tendo produzido o documento: Subsídios para o debate sobre a questão étnico-racial na formação em Serviço Social, cujo o objetivo é oferecer aporte para inclusão e consolidação do debate da questão étnico-racial contribuindo para uma formação em Serviço Social antirracista a partir da ampliação de atividades de ensino, pesquisa e extensão nos âmbitos da graduação e das pós graduação.

A compreensão das relações étnico-raciais enquanto fenômeno histórico e social, e não natural, é fundamental para que possamos acreditar na possibilidade de sua transformação. Esta abordagem pode ser útil para se analisar tanto as práticas interventivas do assistente social quanto a própria configuração do Serviço Social.

O tema tem estado presente no interior da profissão. Está presente, por exemplo, no Código de Ética Profissional, mais especificamente no oitavo princípio, que se refere à "opção por um projeto profisssional vinculado ao processo de construção de uma nova ordem societária, sem dominação-exploração de classe, etnia e gênero". E também na discussão 
sobre a formação profissional, quando se defende a consideração de questões como "as relações de gênero, etnia, valores, aspirações religiosas, expressões artísticas e culturais, além de outros componentes de ordem afetiva, emocional etc.", bem como quando se considera as "diferenciações étnico-raciais" como um dos "impactos econômicos, sociais e políticos peculiares à sociedade brasileira".

Apresentaremos o tratamento dado à questão do racismo pelo Serviço Social, buscando perceber as tendências de sua utilização no debate acadêmico-profissional. "Raça" corresponde ao processo histórico e social de transformação dos sujeitos em homens ou mulheres, brancos, negros ou mestiços, situando-os em condições determinadas no interior de uma sociedade marcada por particularidades e especificidades de gênero e de "raça". Trata-se, portanto, de uma sociedade "generificada" e "racializada".

Como dito acima, a campanha para o triênio 2017-2020 do Conjunto CFESS-CRESS e o Projeto ético-político do Serviço Social, expresso através do Código de Ética do Assistente Social, a Lei de Regulamentação da Profissão e as Diretrizes curriculares do Serviço Social, estabelece como horizonte profissional a construção de uma sociedade verdadeiramente livre e emancipada.

Diante desta assertiva, o posicionamento profissional contra toda e qualquer forma de discriminação por questões de classe social, gênero e raça/etnia se faz urgente. Mais do que não discriminar, faz-se necessário implementar ações concretas no sentido de contribuir com a reparação dos prejuízos causados à população negra, em decorrência da escravidão ocorrida no Brasil.

Desta forma, compreendemos que a defesa das ações afirmativas e mais especificamente, a defesa das cotas raciais, cumpre papel fundamental na construção de um mundo onde sejamos socialmente iguais, humanamente diferentes e totalmente livres, como nos diria Rosa Luxemburgo.

\section{Referências}

ALMEIDA, N. L. T. de. Opção por um projeto profissional vinculado ao processo de construção de uma nova ordem societária, sem dominação, exploração de classe etnia e gênero. Rio de Janeiro: CRESS, 2014

ALMEIDA, M. S. Exercício do Serviço Social sem ser discriminado nem discriminar, por questões de inserção de classe social, gênero, etnia, religião, nacionalidade, opção sexual, idade e condição física. Rio de Janeiro: CRESS, 2014.

BARROCO, M. L. S. Ética: fundamentos sócio-históricos. São Paulo: Cortez, 2008. 
MUNANGA, Kabengele. Uma abordagem conceitual das noções de raça, racismo, identidade e etnia. Palestra proferida no $3^{\circ}$ Seminário Nacional Relações Raciais e Educação, PENESBRJ, 05/11/03 Disponível em: <https://www.geledes.org.br/wp-content/uploads/2014/04/Umaabordagem-conceitual-das-nocoes-de-raca-racismo-dentidade-e-etnia.pdf $>$. Acesso em 17/07/2018 às 18:44.

SANTOS, Rosenverck Estrela. O marxismo e a questão racial no Brasil: reflexões introdutórias. Lutas Sociais (PUCSP), v. 19, p. 100-113, 2015. 